\title{
Singing in the suburbs: point count surveys efficiently reveal habitat associations for nocturnal Orthoptera across an urban-to-rural gradient
}

\author{
Darin J. McNeil ${ }^{1}\left[\right.$ D . Christina M. Grozinger ${ }^{1}$
}

Received: 15 May 2020 / Accepted: 3 September 2020 / Published online: 29 September 2020

(c) The Author(s) 2020

\begin{abstract}
As evidence for global insect population declines continues to amass, several studies have indicated that Orthoptera (grasshoppers, crickets, and katydids) are among the most threatened insect groups. Understanding Orthoptera populations across large spatial extents requires efficient survey protocols, however, many previously established methods are expensive and/or labor-intensive. One survey method widely employed in wildlife biology, the aural point count, may work well for crickets and katydids (suborder: Ensifera) because males produce conspicuous, species-specific mating calls. We conducted repeated point count surveys across an urban-to-rural gradient in central Pennsylvania. Occupancy analyses of ten focal species indicated that, although detection probability rates varied by species from 0.43 to 0.98 , detection rates compounded over five visits such that all focal species achieved cumulative $>0.90$. Factors associated with site occupancy varied among species with some positively associated with urbanization (e.g., Greater Anglewing, Microcentrum rhombifolium), some negatively associated with urbanization (e.g., Sword-bearing Conehead, Neoconocephalus ensiger), and others exhibiting constant occupancy across a habitat gradient (e.g., Common True Katydid, Pterophylla camellifolia). Our community-level analysis revealed that different species' habitat associations interacted such that intermediate levels of urbanization (i.e., suburbs) hosted the highest number of species. Implications for insect conservation: Ultimately, our analyses clearly support the concept that aural point counts paired with static occupancy modeling can serve as an important tool for monitoring night-singing Orthoptera populations. Applications of point count surveys by both researchers and citizen scientists may improve our understanding Ensifera populations and help in the global conservation of these threatened insects.
\end{abstract}

Keywords Crickets $\cdot$ Detection probability $\cdot$ Habitat $\cdot$ Katydids $\cdot$ Occupancy analysis $\cdot$ Surveys

\section{Introduction}

As evidence for global insect population declines continues to amass (Thomas 2016; Hallmann et al. 2017; Leather 2017; van Klink et al. 2020), ecologists are tasked with the increasingly urgent need to establish robust monitoring regimes for sensitive insect taxa (Thomas 2005; Montgomery et al. 2020). Indeed, effective survey protocols have the capacity

Electronic supplementary material The online version of this article (https://doi.org/10.1007/s10841-020-00273-9) contains supplementary material, which is available to authorized users.

Darin J. McNeil

darin.j.mcneil@gmail.com

1 Department of Entomology \& Insect Biodiversity Center, Pennsylvania State University, University Park, PA, USA to form the foundation of long-term monitoring programs that afford conservation biologists insight into population trends (including baseline data) and species habitat associations (Lebuhn et al. 2013; Taron and Ries 2015). Central to the establishment of insect population monitoring programs is the availability of cost-effective survey protocols that yield effective assessments of focal taxa presence across large geographic extents (Yoccoz et al. 2001; Potts et al. 2011). Data resulting from robust population monitoring regimes can, in turn, be used to guide conservation and management strategies (Menz et al. 2013) and help inform the allocation of scarce conservation funding (McIntosh et al. 2018). Further, effective monitoring is useful for identifying habitat needs for sensitive species, an important requisite to the development of species conservation plans (Menz et al. 2013).

Although insect populations appear to be declining across a wide suite of taxa (Hallmann et al. 2017; Leather 2017), 
several studies have highlighted that Orthoptera (grasshoppers, crickets, and katydids) are among the most rapidlydeclining groups of insects (Dirzo et al. 2014; Sánchez-Bayo and Wyckhuys 2019). Indeed, Orthoptera are known to be highly sensitive to variation in habitat conditions (Fischer et al. 1997; Hugel 2012) and have thus been cited as important bioindicators (Riede 1998). In addition to being globally imperiled, Orthoptera make obvious subjects for population monitoring because many of them produce conspicuous mating calls that are species-specific and readily discernable by the human ear (Alexander et al. 1972), especially crickets (Gryllidae) and katydids (Tettigonidae, suborder: Ensifera). While Ensifera populations have been studied extensively in some regards (Gwynne 2001), few efficient, standardized monitoring protocols exist and most involve lethal trapping, time-intensive collection efforts like mark-recapture (reviewed by Gardiner et al. 2005), or expensive automated acoustical sampling techniques (Gibb et al. 2019). Many collection methods (e.g., sweep-netting) are also challenging within densely-vegetated communities, especially for taxa like katydids, many of which are arboreal (Gardiner et al. 2005). Although acoustic sampling methods for crickets and katydids are well-established (Bailey 1991; Gerhardt and Huber 2002; Lehmann et al. 2014), these methods often require specialized audio sampling gear for automated detection (Jeliazkov et al. 2016; Gibb et al. 2019) and complex sonogram identification algorithms (Ganchev and Potamitis 2007; Penone et al. 2013). Clearly, developing a simple and efficient monitoring protocol for Ensifera is paramount for understanding Orthoptera population ecology and for developing long-term population monitoring protocols (Riede 1998; Gardiner et al. 2005).

The development of more efficient monitoring protocols would help elucidate habitat associations for individual Ensifera species across diverse ecological communities (Kéry and Royle 2015; McNeil et al. 2020). Given the community-wide population declines observed in Orthoptera (Dirzo et al. 2014; Sánchez-Bayo and Wyckhuys 2019), an understanding of habitat requirements for these sensitive insect populations may be a conservation priority (Brouwers and Newton 2009). While Orthoptera species in some regions have their habitat associations described at coarse spatial scales (Taylor et al. 2005; Bazelet et al. 2016; Hochkirch et al. 2016), the habitat needs for cricket and katydid species in many regions (e.g., North America) remain completely anecdotal (Shapiro 1998; Gwynne 2001) with no quantitative descriptions available for the majority of taxa. Thus, conservation for Ensifera species or populations is limited by a lack of quantitative data on habitat needs (Brouwers and Newton 2009) which, in turn, are limited by efficient monitoring protocols (Ferson and Burgman 2006). This data gap is critical because species may have strong habitat associations (rather than random habitat use) and taxa differ in their habitat needs (Bazelet et al. 2016).

The conspicuous stridulations produced by singing Ensifera make them excellent candidates for aural population surveys that could be conducted by trained field biologists (Alexander et al. 1972; Riede 1998). Indeed, many vertebrate taxa that produce loud calls are studied using aural surveys as a primary sampling technique. For example, aural-based "point counts" are a common method in avian ecology to detect singing male passerines within habitats of interest (e.g., McNeil et al. 2018, 2020) or along systematically-placed sampling locations (Ralph et al. 1995; Wilson et al. 2012; Sauer et al. 2017). Likewise, nocturnal birds like nightjars (order: Caprimulgiformes, Knight et al. 2016) and shorebirds like Wilson's Snipe (Gallinago delicata) or American Woodcock (Scalopax minor, Kozicky et al. 1954) take place at night and require passive listening for singing males. Similarly, non-avian taxa have been sampled using aural point counts including Eastern Gray Squirrels (Sciurus carolinensis Rahim 2016), and frogs (Dorcas et al. 2009). Point count data are useful for ecological studies because they not only yield data on species occurrence (Ralph et al. 1995), but repeated surveys allow for detection-adjusted occupancy estimation of true species presence, even when a species is not detected perfectly (MacKenzie 2006). Clearly, night-singing Ensifera like crickets and katydids should be amenable to sampling using standard point count surveys, however, the merit of this sampling method remains largely unknown.

To help develop a rapid monitoring protocol and habitat assessment tool for night-singing Orthoptera, we conducted point count surveys across central Pennsylvania and quantified occupancy of singing males across a diverse suite of species. More specifically, we (i) used repeated point count surveys to quantify detection probability and site occupancy of night-singing Orthoptera across an urban-to-rural habitat gradient, (ii) assessed the extent to which repeated point count surveys (conducted by trained field biologists) can be used to quantify song phenology of night-singing Orthoptera, (iii) quantified species-specific habitat associations, and (iv) assessed broad patterns of species richness across our Pennsylvania study area. We discuss these results in terms of sampling protocols for night-singing insects, species phenology and Orthoptera habitat use patterns across varied landscapes.

\section{Materials and methods}

\section{Study area and site selection}

We conducted roadside point count surveys for nightsinging Ensifera in central Pennsylvania, USA (Centre and 
Huntingdon Co.) across an urban-to-rural gradient. Central Pennsylvania consists of a mix of deciduous forest dominated largely by oaks (Quercus spp.) and maples (Acer spp., Albright et al. 2017), row-crop agricultural fields, pastures, and varying degrees of urban and suburban cover types (Cuff 1989; Shultz 1999; Fry et al. 2011). To select sampling locations across our study area, we plotted four line-transects extending $10 \mathrm{~km}$ into each cardinal direction from the centroid of downtown State College, Pennsylvania, using ArcGIS 10.2 (ESRI 2011). Along each line-transect, we plotted points exactly $1 \mathrm{~km}$ apart such that the outermost points were $10 \mathrm{~km}$ from the downtown centroid. We then snapped each point location to the nearest public road with an accessible shoulder. Ultimately, this sampling protocol yielded 40 points along the four line-transects plus one point in the center of our study area (total $\mathrm{N}=41$, Fig. 1).

\section{Point count surveys}

We quantified night-singing Ensifera communities using aural point count surveys, comparable in many ways to those described by Ralph et al. (1995) for songbirds and Dorcas et al. (2009) for chorusing frogs. More specifically, we conducted stationary surveys on roadside shoulders and each consisted of a single observer standing at each point location for the duration of a three-minute survey. All aural surveys were conducted by D. McNeil, who has had extensive experience in quantifying wildlife populations using aural sampling techniques (McNeil et al. 2014, 2018, 2020). During each survey, we recorded all detected Ensifera with the exception of the tree crickets (subfamily: Oecanthinae; see Supporting Table 1). We excluded tree crickets from our sampling because several species in our study area sound quite similar (e.g., Oecanthus latipennis [Riley 1881] vs O. quadripunctatus [Beutenmüller 1894], etc., Alexander et al. 1972). In contrast, nearly all other species of Ensifera stridulations can be discerned fairly easily by the human ear (e.g., Fig. 2, see Supporting Tables 1 and 2). Recordings of all species are readily available online through scientific databases such as the Cornell Lab of Ornithology's Macaulay Library or digital field guides such as Elliot and Hershberger (2007; also see Supporting Table 1). Because our focus was Ensifera that stridulated chiefly after dark, we sampled between sunset and midnight each night and conducted surveys from 27 July through 24 November, a period which encompasses the singing periods for most local Ensifera (Alexander et al. 1972). Over this period, each of our 41 sampling points was surveyed on five separate occasions with each replicate separated by $2-3$ weeks.

In addition to recording the name of each detected Ensifera species, we also recorded for each the estimated distance to nearest stridulating male (rounded to the nearest $5 \mathrm{~m}$ ) and number of individuals detected in five bins: $0,1-2,3-5$, $5-10$, and $>10$. Prior to our formal three-minute count, we allowed one minute to elapse after arriving to each location to allow Ensifera to resume normal singing behavior
Fig. 1 A map of survey locations (bolded white circles) where crickets and katydids were counted with repeated surveys between July and November, 2019 across an urban-to-rural gradient in Centre and Huntingdon Counties, Pennsylvania

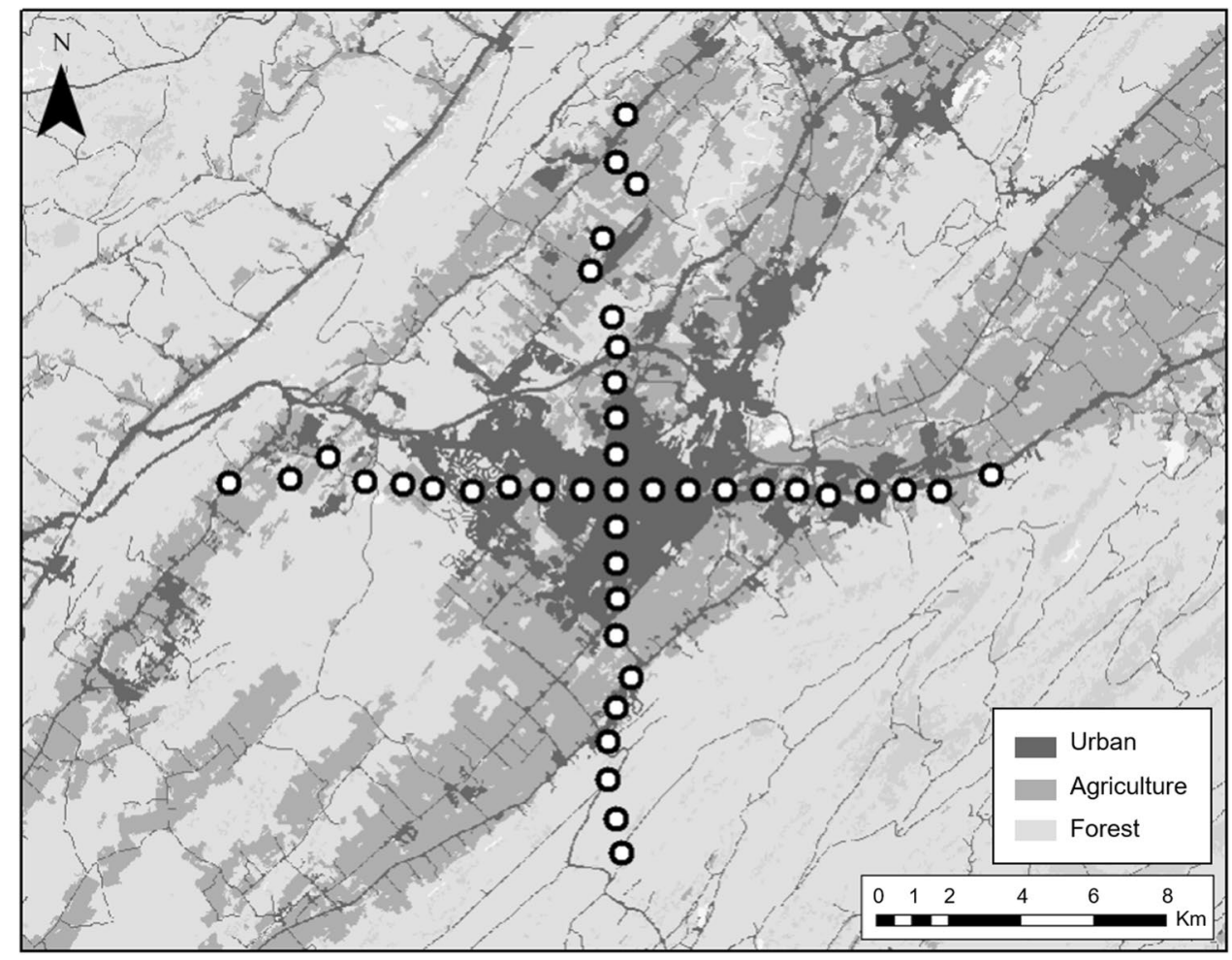


Fig. 2 Sonograms for three species of Neoconocephalus recorded in central Pennsylvania during aural point count surveys in 2019

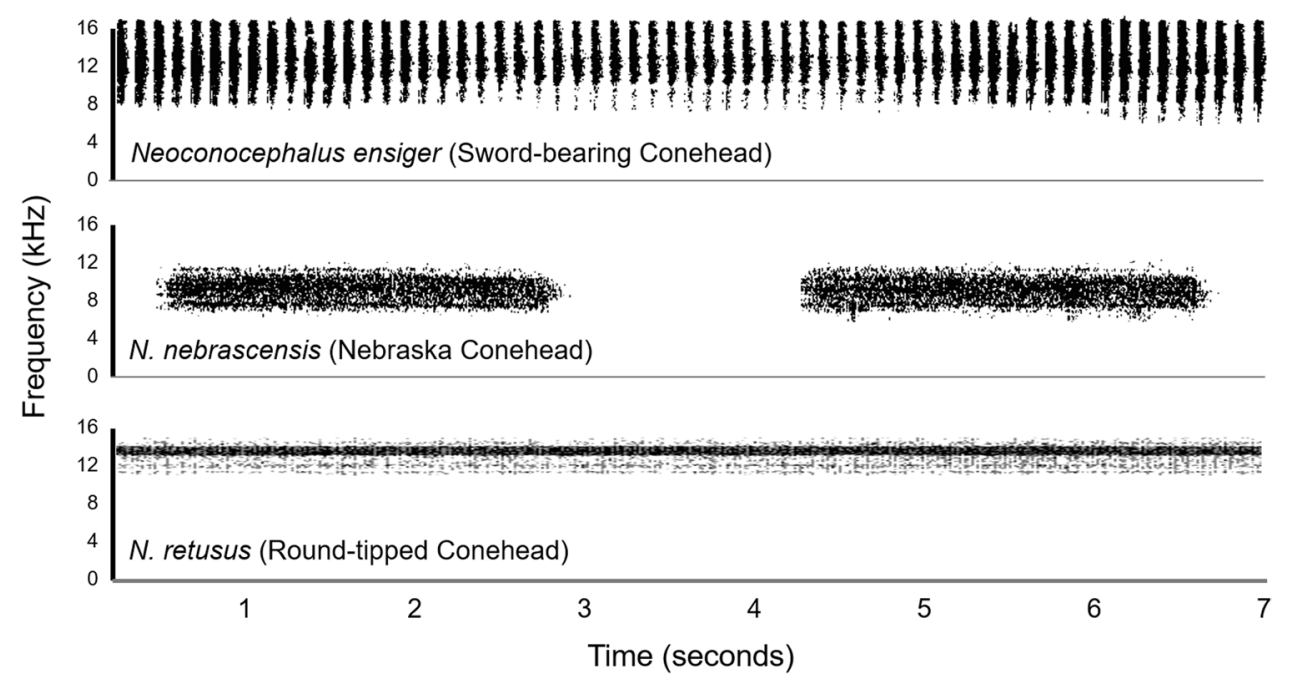

after potential disturbance from the observer traveling to each point location (Ralph et al. 1995). This one-minute 'rest' period afforded the observer the opportunity to record ambient conditions prior to sampling. Specifically, i. minutes since sunset (mss), ii. ordinal date, iii. Beaufort wind index, iv. cloud cover (\%), v. noise index, and vi. temperature.

\section{Quantification of landscape characteristics}

We quantified habitat around survey locations using remotely-sensed data from the National Land Cover Database (NLCD, Fry et al. 2011). We summarized land cover at the $100 \mathrm{~m}$ radius scale for the following land cover classes: 1. forest, 2. developed, and 3. agriculture. We used a $100 \mathrm{~m}$ radius because this is the maximum distance within which majority of Ensifera were detected. Each covariate was modeled as percent cover within a $100 \mathrm{~m}$ radius buffer around each point location.

\section{Statistical analyses}

To assess species detection probability, occupancy probability, and habitat associations, we created single-season occupancy models in the $\mathrm{R}$ package unmarked (Fiske and Chandler 2011; R Core Team 2020). Occupancy models provide an excellent framework for assessing species presence as they independently model probability of occupancy (i.e., presence at a site) and probability of detection (i.e., detecting a species, given it is present; MacKenzie 2006; Kéry and Royle 2015). With this in mind, there are several assumptions associated with occupancy models (see MacKenzie 2006): (1) detections at each site are independent of detections at other sites (i.e., independence), (2) detection probability is constant across sites or otherwise incorporated into models as covariates (i.e., homogenous detection), (3) occupancy probability is constant across sites or otherwise incorporated into models as covariates (i.e., homogenous occupancy), and (4) sites do not change occupancy state during the sampling period (i.e., site closure).

Over the course of our five sampling visits, we quickly noticed that during our fifth sampling round (4-24 November), most sites were apparently unoccupied by all species, and thus we only modeled species occupancy using the first four sampling periods. Moreover, we only modeled species with enough detections for model convergence (e.g., $>20 \%$ naïve occupancy, MacKenzie 2006). Although we observed 18 species, this guideline ultimately allowed us ten Ensifera species with which to model occupancy including five katydids: Pterophylla camellifolia (Fabricius 1775; Common True Katydid), Microcentrum rhombifolium (Saussure 1859; Greater Anglewing), Neoconocephalus nebrascensis (Bruner 1981; Nebraska Conehead), N. retusus (Scudder 1878; Round-tipped Conehead), and N. ensiger (Harris 1841; Sword-bearing Conehead), and five crickets: Hapithus saltator (Uhler 1864; Jumping Bush Cricket), Gryllus pennsylvanicus (Burmeister 1838; Fall Field Cricket), Eunemobius carolinus (Scudder 1877; Carolina Ground Cricket), Allonemobius allardi (Alexander and Thomas 1959; Allard's Ground Cricket), and A. fasciatus (De Geer 1773; Striped Ground Cricket, see Supporting Table 2 for a full list of species recorded). Of these ten species, four were detected sufficiently often that we modeled observations from sampling occasions 1-4 (all three ground crickets and G. pennsylvanicus). Although we initially tried to model all species using sampling occasions 1-4, these models were often highly overdispersed or did not converge because of the high degree of variation in individual species song phenology. $H$. saltator was rarely detected during the first sampling occasion so we modeled its occupancy using sampling occasions 2-4. Preliminary katydid occupancy modeling indicated that analyses incorporating data from all four occasions were 
highly overdispersed (i.e., $\widehat{c}>1.0$ ). To ensure the data underlying our katydid models conformed to occupancy assumptions, we modeled species during time periods when visit-specific naïve occupancy appeared largely constant. We modeled N. nebrascensis and $P$. camellifolia with sampling visits $1-2 ; M$. rhombifolium and $N$. retusus with visits $2-3$, and $N$. ensiger with visits $1-3$. To ensure that our analysis was focused on only species detected near each point location, we also removed detections for species where the closest individual was $>100 \mathrm{~m}$ from the observer.

For each of our ten focal species, we created occupancy models allowing for all possible combinations of up to one covariate on detection probability $(p)$ and up to one covariate on occupancy probability $(\psi)$. Our model set also included null (intercept-only) models on both $p$ and $\psi$. We restricted the number of parameters in this way to avoid overparameterization of our models. We considered the following covariates on detection probability: i. minutes since sunset (mss), ii. ordinal date, iii. Beaufort wind index (estimated in the field), iv. cloud cover (\%, visually estimated to nearest $25 \%$ ), v. noise index (adapted from Dorcas et al. 2009), and vi. temperature. We restricted our analyses to only one detection covariate to avoid specifying overly complex models into our analyses. We likewise considered the following covariates on occupancy probability: i. percent forest cover, ii. percent agriculture cover, and iii. percent developed cover. To rank models for each species, we used an information theoretic approach for model selection (Akaike's Information Criterion adjusted for small sample size, $\mathrm{AIC}_{c}$, Burnham and Andersen 2002). For competing models $\left(\Delta \mathrm{AIC}_{\mathrm{c}}<2.0\right)$, we also examined and report covariate $\beta$ coefficient $95 \%$ confidence intervals and interpreted those that overlapped as zero as weak biological effects (Burnham and Andersen 2002; MacKenzie 2006). For the top-ranked model in each candidate set, we estimated overdispersion using the MacKenzie and Bailey Goodness-of-fit Test for Single Season Occupancy Models (i.e., c c, Kéry and Royle 2015). For overdispersed candidate models, we ranked models using Quasi $\mathrm{AIC}_{\mathrm{c}}\left(\mathrm{QAIC}_{\mathrm{c}}\right)$ which further penalizes overly complex models beyond the penalty applied by $\mathrm{AIC}_{\mathrm{c}}$ (Burnham and Andersen 2002). We used $\mathrm{QAIC}_{\mathrm{c}}$ to rank seven of our ten model sets due to minor overdispersion (mean $\widehat{c}=1.6$, range: $0.75-3.25$ ). Prior to each analysis, we scaled all variables to improve model convergence (Sokal and Rohlf 1969; Kéry and Royle 2015).

In addition to modeling each species individually, we modeled species richness as a function of $i$. percent forest cover, ii. percent agriculture cover, and iii. percent developed cover. We estimated species richness for all species detected at each site (see Supporting Table 2) where we considered any species detected at least once across five sampling periods to be 'confirmed present' and richness was the sum of all species confirmed present at any site over time. Using species richness as a response variable to percent land cover, we created simple linear models in $\mathrm{R}$ and ranked models using the same Information Theoretic approach described above. Herein, we tested all linear and quadratic relationships between land cover and species richness as well as an intercept-only null model.

\section{Results}

By sampling 41 locations each five times between 27 July and 24 November, we conducted a total of 205 three-minute Ensifera point counts for a cumulative sampling time of $10.25 \mathrm{~h}$ (615 total minutes, $15 \mathrm{~min} /$ location). Surveys spanned a gradient of urbanization (mean $45 \%$ cover, range $0-100 \%$ ) with non-urban cover chiefly a mixture of secondary forest (mean $21 \%$ cover, range $0-93 \%$ ) and agriculture (mean $24 \%$ cover, range $0-84 \%$, Fig. 1). Over these surveys, we observed a minimum of 857 individual singing males across 18 different species (Supporting Table 2). Of these, ten species had sufficient detections for statistical modeling and thus were included in subsequent analyses.

\section{Phenology}

Seven of our ten focal species (those species with enough detections to model) were already singing when our sampling began in July and three species initiated singing after sampling began (Fig. 3). Although we are unable to assess the total song periods for species already singing when our sampling began, of the three species that initiated singing after our sampling began, there was substantial variation in their duration of singing: song periods lasted 36, 68, and 82 days for $H$. saltator, $M$. rhombifolium, and $N$. retusus (respectively). Early September (Ordinal dates 245-246) marked the approximate peak of detected Ensifera species richness during the 2019 survey season as all 10 focal species were detected over these nights. Thereafter, nightly species richness declined linearly until mid-November (ordinal date 313) when detections for all species ceased completely (Fig. 3).

\section{Detection and occupancy probability}

Detection probability varied among species ranging from 0.43 (M. rhombifolium, 95\% CI 0.31-0.55) to 0.98 (H. saltator, 95\% CI 0.89-0.99) (Fig. 4, Table 1). Rates compounded such that all ten of our focal species could achieve cumulative detection probability rates of $>0.90$ after five replicates (Fig. 4) though most species achieved this rate with fewer replicates. Furthermore, although our surveys were three minutes in length, $89.93 \%$ of species detections were made within 1 min of the survey's beginning and $95.38 \%$ were 
Fig. 3 Mapped phenology for ten species of cricket and katydid detected with repeated surveys across an urban-to-rural gradient in Centre and Huntingdon Counties, Pennsylvania detected from July to November, 2019. Each sampling date is shown as a light gray vertical bar. For each species is shown maximum counts for date period

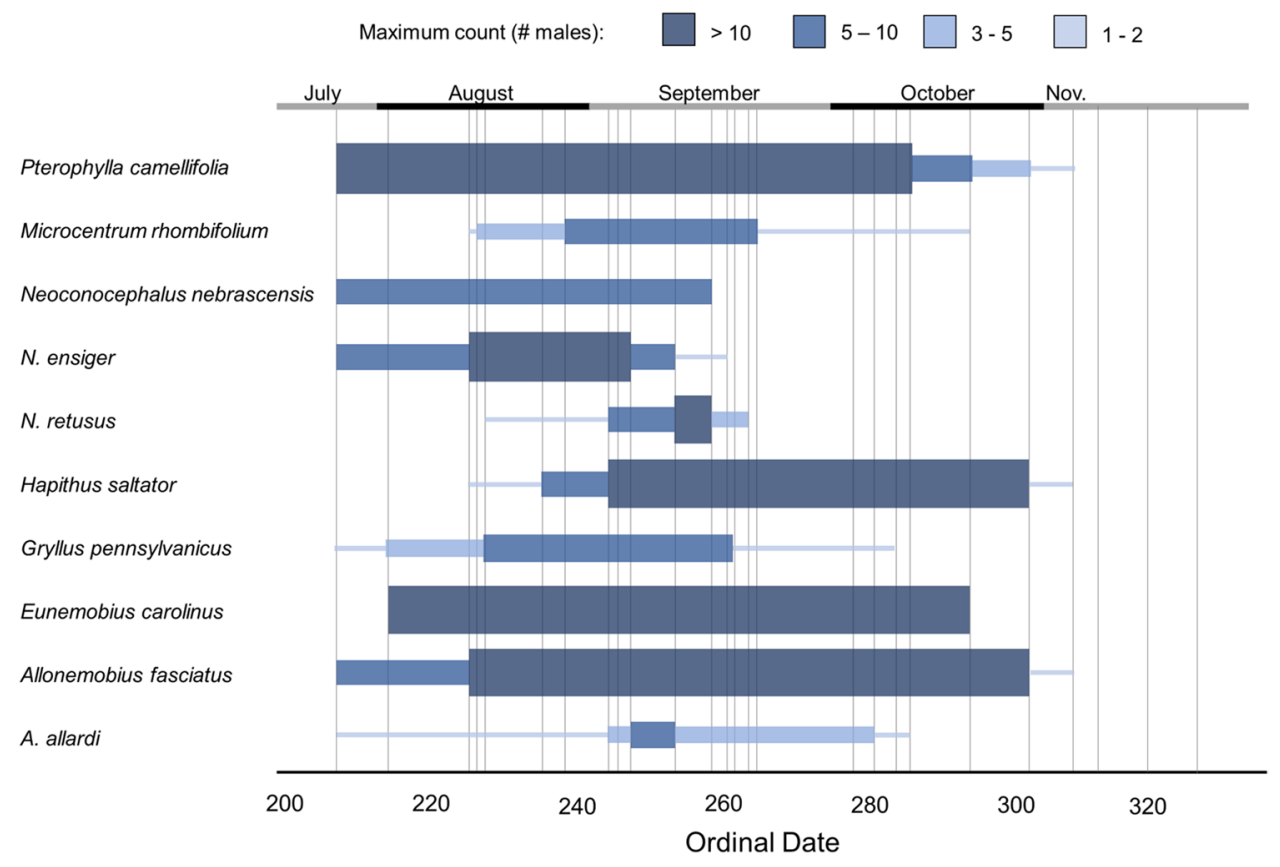

made within 2 min of survey time. Additionally, species varied in the factors that impacted $\hat{p}$ (Table 1) with several species exhibiting a negative relationship between detection probability and survey date.

Like detection probability, estimates of occupancy probability $(\widehat{\psi})$ varied among species ranging from $0.33(N$. ensiger, 95\% CI 0.19-0.55) to 0.98 (P. camellifolia, 95\% CI 0.68-0.99, Fig. 4, Table 1). Habitat associations also varied among Ensifera species (Fig. 5). For example, sites with more developed land cover hosted higher estimates of $\widehat{\psi}$ for $M$. rhombifolium and $H$. saltator (Fig. 5, Table 1). In contrast, both $N$. ensiger and $N$. retusus were negatively associated with developed land cover. With these habitat patterns in mind, candidate model sets for several species indicated that $\widehat{\psi}$ remained largely constant (e.g., E. carolinus, $P$. camellifolia, etc.) suggesting that highly urban areas were just as likely to host a focal species as heavily forested locations.

\section{Species richness}

Our top species richness model included a quadratic term for developed land cover with both the linear and quadratic $\beta$ coefficients characterized by $95 \%$ confidence intervals that did not overlap zero (Table 2). There were no competing models in the species richness model set. Predictions using this top-ranked model suggested that Ensifera species richness was greatest at intermediate levels of developed land cover (i.e., suburbs) while heavily developed and predominantly forested locations hosted the lowest species richness (Fig. 6). Ensifera richness ranged from low values of 5.96 and 6.07 species at $100 \%$ and $0 \%$ development (respectively) with richness increasing by a factor of 1.5 (richness $>9$ ) at intermediate levels (38-60\%) of developed land cover at the $100 \mathrm{~m}$ radius scale (Fig. 6).

\section{Discussion}

Effective population monitoring for threatened species is of enormous importance for global biodiversity conservation (Yoccoz et al. 2001; Potts et al. 2011; Menz et al. 2013). Our study provides the first empirical demonstration that aural point counts conducted by field biologists may serve as an important survey method to study cricket/katydid populations because they are efficient, accurate, and nondestructive. In our region, it was possible to simultaneously and non-destructively monitor 18 different species, though only 10 of these were common enough for subsequent analyses. Efficiency was accomplished by coupling high rates of species detection probability (Fig. 4) with a brief survey duration (three minutes) while requiring essentially no special equipment. While alternative aural sampling methods are well-established in Ensifera literature (e.g., Gibb et al. 2019), most require expensive recording equipment and highly technical analyses to extract and analyze recordings (Penone et al. 2013; Bradfer-Lawrence et al. 2019). Nonlethal sampling methods like point count surveys are also desirable for studying species of conservation concern (Rose et al. 1994) whereby legal and ethical concerns may preclude the collection of live specimens. Indeed, the merit of aural point count surveys as a technique to rapidly quantify animal populations will come as no surprise to vertebrate biologists 
Table 1 Occupancy models for five species of cricket and katydids observed in Centre and Huntingdon Counties, Pennsylvania from July to November, 2019

\begin{tabular}{|c|c|c|c|c|c|c|}
\hline Model & $\mathrm{k}$ & $\mathrm{QAIC}_{\mathrm{c}}$ & $\Delta \mathrm{QAIC}_{\mathrm{c}}$ & $\mathrm{w}$ & Cum wt & LL \\
\hline \multicolumn{7}{|l|}{ Crickets (family: Gryllidae) } \\
\hline \multicolumn{7}{|l|}{ Allonemobius allardi } \\
\hline$p\left(\right.$ date $\left.^{(-)}\right), \psi()$. & 4 & 175.19 & 0.00 & 0.28 & 0.28 & -83.04 \\
\hline$p\left(\right.$ date $\left.^{(-)}\right), \psi($ developed $)$ & 5 & 175.64 & 0.45 & 0.23 & 0.51 & -81.96 \\
\hline$p\left(\right.$ date $\left.^{(-)}\right), \psi($ agriculture $)$ & 5 & 176.18 & 0.98 & 0.17 & 0.68 & -82.23 \\
\hline \multicolumn{7}{|l|}{ Allonemobius fasciatus } \\
\hline$p\left(\right.$ date $\left.^{(-)}\right), \psi\left(\right.$ forest $\left.^{(-)}\right)$ & 5 & 83.81 & 0.00 & 0.36 & 0.36 & -36.05 \\
\hline$p\left(\right.$ temp $\left.^{(+)}\right), \psi\left(\right.$ forest $\left.^{(-)}\right)$ & 5 & 85.48 & 1.68 & 0.16 & 0.52 & -36.88 \\
\hline$p(),. \psi\left(\right.$ forest $\left.^{(-)}\right)$ & 4 & 85.58 & 1.78 & 0.15 & 0.66 & -38.24 \\
\hline \multicolumn{7}{|l|}{ Eunemobius carolinus } \\
\hline$p(),. \psi()$. & 3 & 72.15 & 0.00 & 0.16 & 0.16 & -32.75 \\
\hline$p\left(\right.$ date $\left.^{(-)}\right), \psi()$. & 4 & 72.89 & 0.73 & 0.11 & 0.28 & -31.89 \\
\hline$p\left(\right.$ date $\left.^{(-)}\right), \psi()$. & 4 & 73.03 & 0.88 & 0.11 & 0.38 & -31.96 \\
\hline \multicolumn{7}{|l|}{ Gryllus pennsylvanicus } \\
\hline$p\left(\right.$ date $\left.^{(-)}\right), \psi()$. & 4 & 121.90 & 0.00 & 0.32 & 0.32 & -56.39 \\
\hline$p\left(\right.$ date $\left.^{(-)}\right), \psi($ agriculture $)$ & 5 & 123.56 & 1.67 & 0.14 & 0.45 & -55.93 \\
\hline \multicolumn{7}{|l|}{ Hapithus saltator } \\
\hline$p(),. \psi\left(\right.$ developed $\left.^{(+)}\right)$ & 4 & 25.63 & 0.00 & 0.34 & 0.34 & -8.26 \\
\hline$p($ cloud $), \psi\left(\right.$ developed $\left.^{(+)}\right)$ & 5 & 27.16 & 1.53 & 0.16 & 0.49 & -7.72 \\
\hline$p$ (wind), $\psi\left(\right.$ developed $\left.^{(+)}\right)$ & 5 & 27.38 & 1.75 & 0.14 & 0.64 & -7.83 \\
\hline \multicolumn{7}{|l|}{ Katydids (family: Tettigoniidae) } \\
\hline \multicolumn{7}{|l|}{ Neoconocephalus ensiger } \\
\hline$p\left(\right.$ date $\left.^{(-)}\right), \psi\left(\right.$ developed $\left.^{(-)}\right)$ & 4 & 104.01 & 0.00 & 0.25 & 0.25 & -47.45 \\
\hline$p\left(\right.$ date $\left.^{(-)}\right), \psi($ agriculture $)$ & 4 & 105.19 & 1.18 & 0.14 & 0.40 & -48.04 \\
\hline$p\left(\right.$ mss $\left.^{(-)}\right), \psi\left(\right.$ developed $\left.^{(-)}\right)$ & 4 & 105.50 & 1.49 & 0.12 & 0.52 & -48.2 \\
\hline \multicolumn{7}{|l|}{ Neoconocephalus retusus } \\
\hline$p\left(\right.$ temp $\left.^{(+)}\right), \psi\left(\right.$ developed $\left.^{(-)}\right)$ & 5 & 46.03 & 0.00 & 0.6 & 0.6 & -17.16 \\
\hline$p\left(\right.$ temp $\left.^{(+)}\right), \psi\left(\right.$ agriculture $\left.^{(+)}\right)$ & 5 & 47.13 & 1.10 & 0.35 & 0.95 & -17.71 \\
\hline Model & $\mathrm{k}$ & $\mathrm{Q} / \mathrm{AIC}_{\mathrm{c}}$ & $\Delta \mathrm{Q} / \mathrm{AIC}_{\mathrm{c}}$ & $\mathrm{w}$ & Cum wt & $\mathrm{LL}$ \\
\hline \multicolumn{7}{|l|}{ Neoconocephalus nebrascensis } \\
\hline$p\left(\right.$ date $\left.^{(-)}\right), \psi()$. & 3 & 89.45 & 0.00 & 0.35 & 0.35 & -41.4 \\
\hline$p\left(\right.$ date $\left.^{(-)}\right), \psi($ forest $)$ & 4 & 90.83 & 1.38 & 0.18 & 0.53 & -40.86 \\
\hline$p\left(\right.$ date $\left.^{(-)}\right), \psi($ development $)$ & 4 & 90.85 & 1.40 & 0.18 & 0.71 & -40.87 \\
\hline \multicolumn{7}{|l|}{ Pterophylla camellifolia } \\
\hline$p($ temp $), \psi()$. & 3 & 64.91 & 0.00 & 0.10 & 0.10 & -29.13 \\
\hline$p(),. \psi()$. & 2 & 65.21 & 0.30 & 0.09 & 0.19 & -30.45 \\
\hline$p($ temp $), \psi($ agriculture $)$ & 4 & 65.39 & 0.48 & 0.08 & 0.27 & -28.14 \\
\hline$p($ date $), \psi()$. & 3 & 65.50 & 0.59 & 0.07 & 0.34 & -29.43 \\
\hline$p(),. \psi($ agriculture $)$ & 3 & 65.56 & 0.65 & 0.07 & 0.41 & -29.45 \\
\hline$p$ (temp), $\psi($ forest $)$ & 4 & 65.65 & 0.74 & 0.07 & 0.48 & -28.27 \\
\hline$p(),. \psi($ forest $)$ & 3 & 65.82 & 0.90 & 0.06 & 0.55 & -29.58 \\
\hline$p$ (date), $\psi($ agriculture $)$ & 4 & 65.98 & 1.07 & 0.06 & 0.61 & -28.44 \\
\hline$p$ (date), $\psi($ (forest $)$ & 4 & 66.24 & 1.33 & 0.05 & 0.66 & -28.57 \\
\hline \multicolumn{7}{|l|}{ Microcentrum rhombifolium } \\
\hline$p\left(\right.$ date $\left.^{(+)}\right), \psi\left(\right.$ developed $\left.^{(+)}\right)$ & 5 & 63.25 & 0 & 0.49 & 0.49 & -25.77 \\
\hline
\end{tabular}

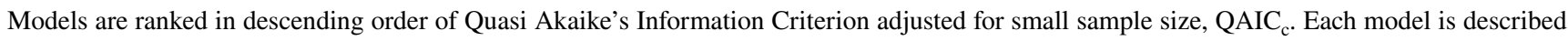
with two components: detection probability $(p)$ and occupancy probability $(\psi)$, with covariates on each model component shown in parentheses. We considered each of six covariates on $p$ : (i) date, (ii) minutes since sunset (mss), (iii) cloud cover (cloud), (iv) Beaufort wind index (wind), (v) noise index (noise), and (vi) temperature (temp). We considered each of three covariates on $\psi$. (i) percent developed cover (100 $\mathrm{m}$ radius), (ii) percent forest cover, and (iii) percent agriculture cover. We also considered intercept-only (.) model components for both $p$ and $\psi$. Covariate $\beta$ 95\% confidence intervals that did not include zero are bolded while those overlapping zero are non-bold. For covariates with $\beta 95 \%$ confidence intervals that did not include zero, relationship directions are depicted with superscript signs. Also shown for each model are: number of model parameters (k), model weight (w), cumulative model weight (Cum. wt.), and Log likelihood (LL) 

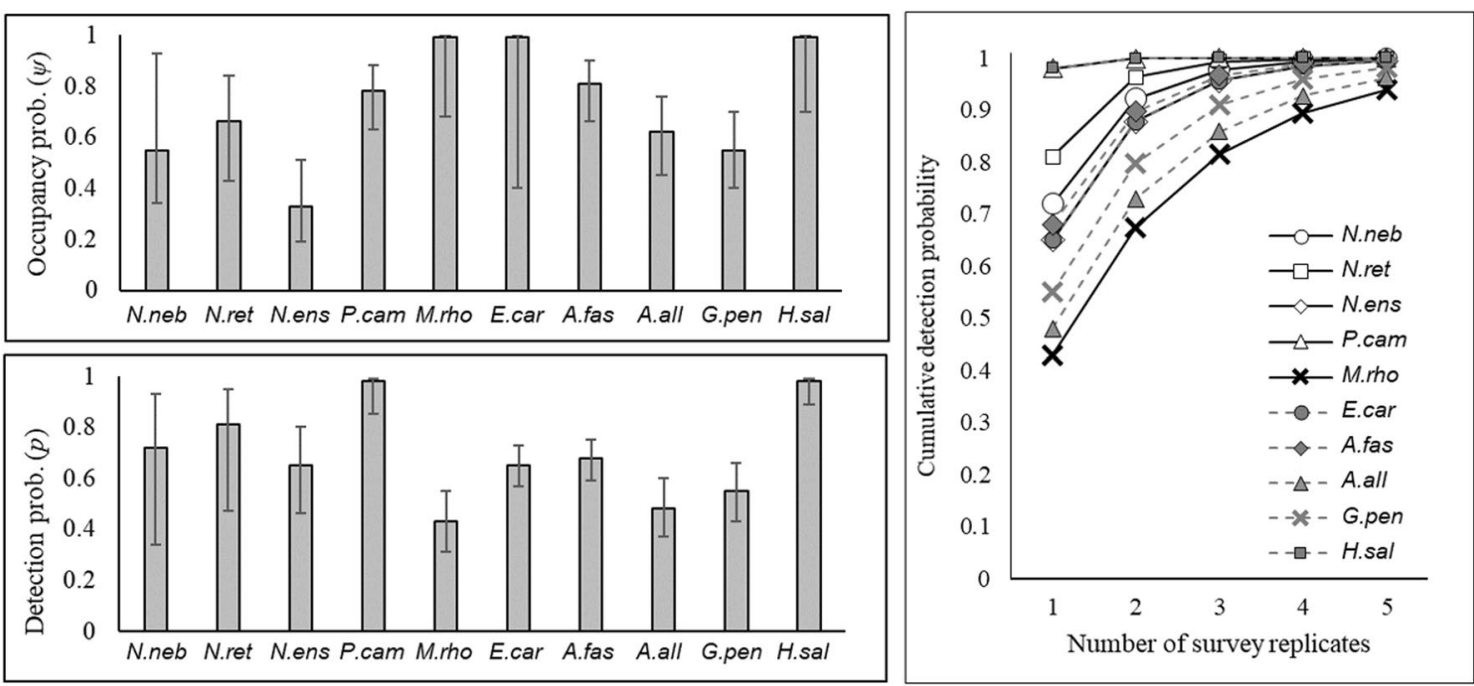

Fig. 4 Point estimates of occupancy probability (top left) and detection probability (lower left) for occupancy models of each of ten species: Neoconocephalus nebrascensis (N.neb), N. retusus (N.ret), N. ensiger (N.ens), Pterophylla camellifolia (P.cam), Microcentrum rhombifolium (W.rho), Eunemobius carolinus (E.car), Allonemobius fasciatus (A.fas), A. allardi (A.all), Gryllus pennsylvanicus (G.pen) and Hapithus saltator (H.sal). Additionally shown are cumulative rates of estimated detection probability for each species extrapolated over 1-5 survey replicates (right). Error bars represent 95\% confidence intervals
Fig. 5 Top-ranked patterns of occupancy for four representative species of Ensifera: Neoconocephalus retusus, (upper left), Allonemobius fasciatus (upper right), N. ensiger (lower left), and Hapithus saltator (lower right). Percent cover values as each independent variable are quantified at the $100 \mathrm{~m}$ radius. Mean model estimates are shown with a solid black line while dashed lines represented $95 \%$ confidence intervals
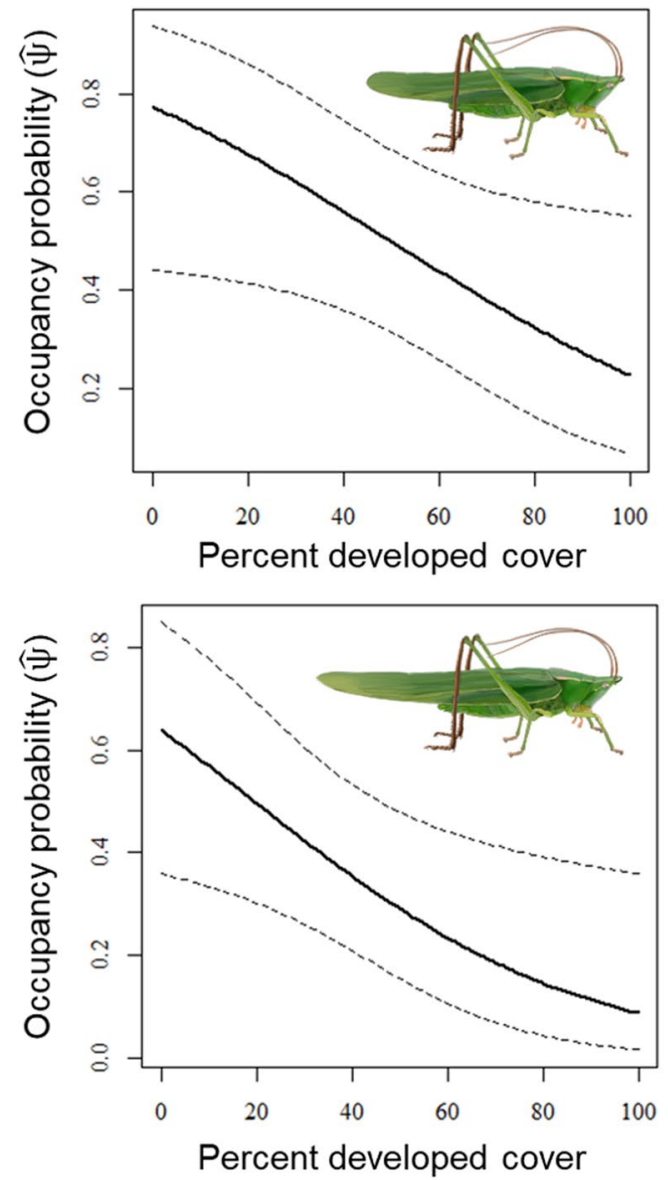
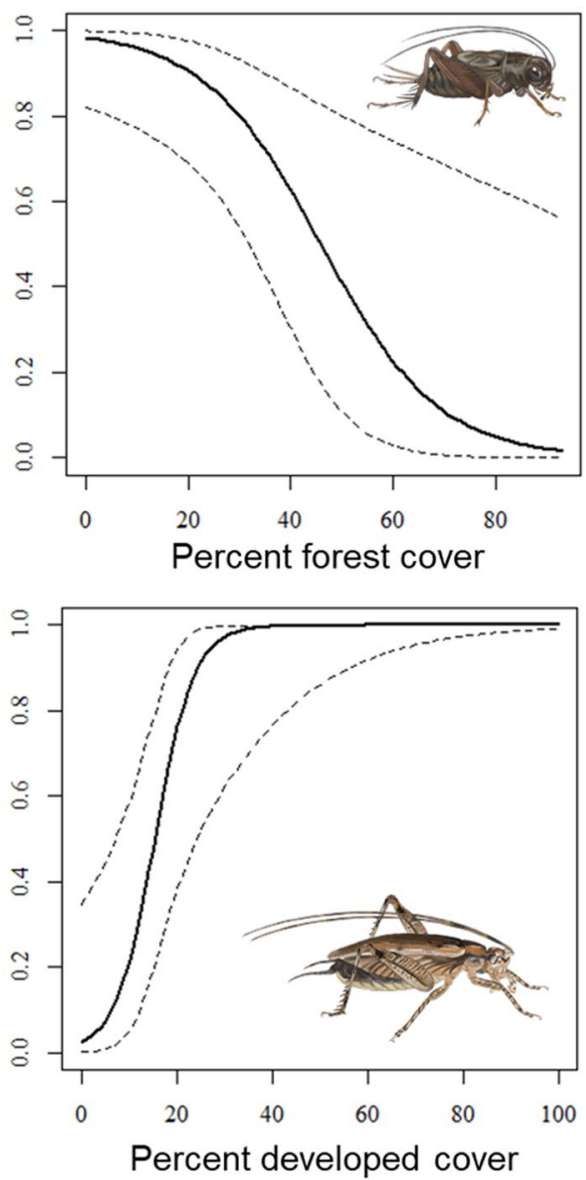
Table 2 Simple linear models of species richness for 18 species of Ensifera (families: Gryllidae, Tettigoniidae) observed in Centre and Huntingdon Counties, Pennsylvania from July to November, 2019

\begin{tabular}{lllllll}
\hline Model & $\mathrm{k}$ & $\mathrm{AIC}_{\mathrm{c}}$ & $\Delta \mathrm{AIC}_{\mathrm{c}}$ & $\mathrm{w}$ & $\mathrm{Cum} w \mathrm{LL}$ \\
\hline Developed $^{2}$ & 4 & 177.79 & 0.00 & 0.87 & 0.87 & -84.34 \\
Agriculture $^{2}$ & 4 & 183.84 & 6.05 & 0.04 & 0.91 & -87.36 \\
Forest $^{2}$ & 4 & 184.52 & 6.72 & 0.03 & 0.94 & -87.7 \\
Intercept-only $_{\text {Agriculture }}$ & 2 & 184.72 & 6.93 & 0.03 & 0.97 & -90.2 \\
Forest & 3 & 186.18 & 8.39 & 0.01 & 0.98 & -89.77 \\
Developed & 3 & 186.48 & 8.69 & 0.01 & 0.99 & -89.92 \\
\hline
\end{tabular}

Models are ranked in descending order of Akaike's Information Criterion adjusted for small sample size $\left(\mathrm{AIC}_{\mathrm{c}}\right)$. We considered each of three covariates on $\psi$. (i) percent developed cover (100 m radius), (ii) percent forest cover, and (iii) percent agriculture cover. Both linear $(\mathrm{x})$ and quadratic $\left(\mathrm{x}^{2}\right)$ forms of each covariate are considered. We also considered an intercept-only (null) model on species richness. Also shown for each model are: number of model parameters (k), model weight (w), cumulative model weight (Cum. wt.), and Log likelihood (LL)

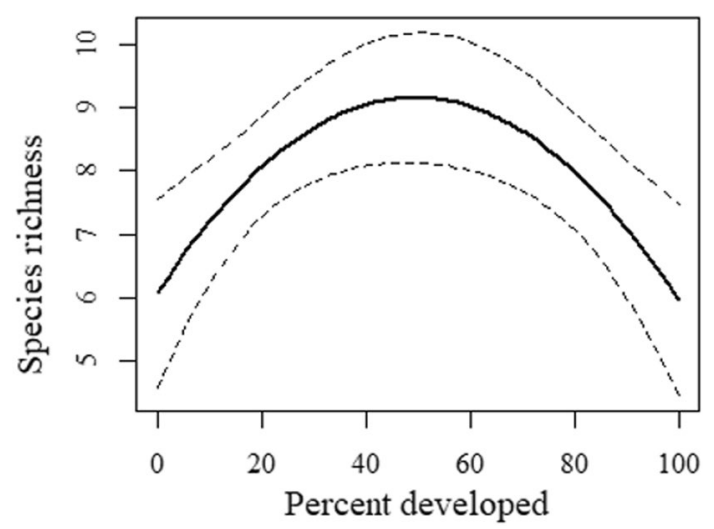

Fig. 6 The best-ranked model of Ensifera species richness across an urban-to-rural gradient in Centre and Huntingdon Counties, Pennsylvania detected from July to November, 2019. Mean model estimates are shown with a solid black line while dashed lines represented $95 \%$ confidence intervals

who have leveraged the method for decades (Gooch et al. 2006; McNeil et al. 2014, 2020). Our analysis, thereby, contributes to a rich body of literature supporting the use of point count surveys to sample animals with conspicuous breeding displays-including night-singing Orthoptera.

By analyzing aural point count data with occupancy models, we provide the first quantitative glimpse into the habitat needs for a variety of night-singing Orthoptera across eastern North America. For example, two later-singing species (Fig. 3), H. saltator and M. rhombifolium, were positively associated with developed habitats while others like $N$. ensiger exhibited the opposite pattern (Fig. 5). In contrast, we found no habitat patterns on occupancy for some species (e.g., P. camellifolia) suggesting that these species were essentially ubiquitous across the habitats we sampled. This latter point is interesting because habitat loss (via conversion to urban and agriculture) is recognized as one of the major threats to biodiversity, the world over (Andrén 1994; Jantz et al. 2015). Although the geographic scope of our study is limited, our results suggests that some native Ensifera species may be highly generalistic in that they occur both in expansive forests and heavily degraded landscapes. Further studies could investigate how the behavior, physiological requirements and natural history of these species contribute to their different habitat needs. Further, these results lay the groundwork for additional studies to better understand the spatial scale at which Ensifera use habitat, although we assessed patterns at the $100 \mathrm{~m}$ scale, it is entirely likely that smaller scales (for diminutive, mostly flightless species like Allonemobius spp.) or larger scales (for large, flighted species like Microcentrum spp.) might be more appropriate (Cody 1985; Orians and Wittenberger 1991).

The capacity to rapidly quantify species-specific habitat associations marks a fundamental advance in understanding of North American Ensifera because most species have no formal descriptions of habitat use (Gwynne 2001). Our study revealed numerous habitat associations that differed among species with some preferring agriculturally-dominated landscapes (e.g., N. ensiger) whereas others preferred habitats dominated by urban cover (e.g., H. saltator). Although some of these habitat associations have been anecdotally described (Shaw et al. 1982; Shaw and Carlson 1969), our work is the first to empirically describe habitat for the species in central Pennsylvania and provides a simple framework for better understanding Ensifera habitat across many regions/ contexts. Our community-level analysis revealed that different species' habitat associations interacted such that intermediate levels of urbanization hosted the highest number of species. This pattern is explained by the 'Intermediate Disturbance Hypothesis' (Connell 1978) which states that habitats with intermediate levels of disturbance host the greatest number of habitat niches and can support the most species as compared to heavily disturbed (e.g., urbanized) or totally undisturbed ecosystems (e.g., natural, Connell 1978). With this in mind, our study was not designed to test this 
hypothesis as we only sampled an area $\sim 10 \mathrm{~km}$ radius, it is therefore possible that, these patterns would not hold at greater extents (e.g., across states, biogeographic realms, etc.). Indeed, disturbance associations are known to vary across scales and species groups (e.g., Mayor et al. 2012), so this result is likely at least somewhat context specific.

One important strength of our analytical approach is that it allows for simultaneous estimation of detection probability and occupancy probability of multiple species, 18 in our case (MacKenzie et al. 2005). While auditory surveys for Ensifera have been conducted previously (Riede 2018), few have incorporated model-based accounts of detection probability (but see Franklin et al. 2009). Failure to account for detection error during animal surveys usually leads to underestimation of site occupancy rates (MacKenzie et al. 2005) and may even suggest erroneous habitat relationship associations (MacKenzie 2006; McNeil et al. 2019). Although field sampling methods like sweep netting and trapping may provide relatively straightforward means for assessing Orthoptera communities (Gray and Treloar 1933; Spafford and Lortie 2013), aural methods have the important benefit of being non-lethal (Ralph et al. 1995), lethal methods may violate the assumption of closure as animals are removed from sampling sites for collection (Otto et al. 2013) which would bias estimates of $\hat{p}$ and, thereby, impact estimates of $\hat{\psi}$. We accounted for several important sources of variation in our models: survey time, date, wind, cloud cover, ambient noise, and temperature. Although not all of these covariates were useful in predicting variation in detection probability in our analyses, several consistent patterns emerged: multiple species demonstrated declining detection probability with advancing date and increased detection with temperature. These patterns are largely intuitive and suggest that detection probability was maximized during the early season (e.g., August-September) and on warm nights. With this in mind, accounting for detection probability in a modeling framework, as we have here, is important even when detection covariates are not included to ensure robust estimates of site occupancy over a study area (MacKenzie et al. 2005; McNeil et al. 2014).

While our study demonstrates that aural point counts paired with occupancy modeling provides an excellent approach to quantify habitat ecology for North American Ensifera, there are several important considerations that may make these sampling methods unsuitable in some circumstances. For instance, if singing males regularly relocate during a breeding season (i.e., enter or exit sites mid-season), this would constitute a closure violation and bias estimates of detection probability (McNeil et al. 2014). Although we did not assess individual movement patterns, previous research has indicated many species are highly territorial (e.g., P. camellifolia, Shaw 1968; N. ensiger, Shaw et al. 1982) indicating that, for most species, within-season emigration/immigration was relatively rare. An additional challenge associated with aural point counts is that they are likely more difficult to apply in regions where many Orthoptera sound alike (e.g., the Neotropics, Diwakar et al. 2007). This is especially true in circumstances where there may be cryptic species, hybrid zones, etc. (e.g., Orci et al. 2010). In such circumstances, alternatives might be to identify insect song 'morpho-types' or to focus primarily on automated recording/detection methods (Lehmann et al. 2014). Another challenge associated with aural point count surveys is that true "counts" (number of singing males) were difficult to conduct, we found that, beyond $\sim 10$ males, individuals become nearly impossible to easily discern. As done here, other survey protocols for night-singing wildlife (e.g., anurans) 'bin' counts to capture some variation in abundance without necessitating true animal counts (Dorcas et al. 2009; Nelson and Graves 2004). One final limitation worth considering here is associated with sampling Ensifera species that produce very quiet (or very high-pitched) songs; first, these quiet species may be difficult to detect amongst a loud chorus of other Ensifera (e.g., P. camellifolia). Second, such species may also be disturbed by the approaching observer and remain silent during the observation period (with farther individuals being too quiet to detect). In both cases, automated recorders might prove more effective than aural point counts (Lehmann et al. 2014). With that in mind, all species in our study were detected at minimum distances of 0 to $10 \mathrm{~m}$, indicating that they were willing to sing in close proximity to the observer, and all but one species were detected at a maximum distance greater than $20 \mathrm{~m}$, suggesting that they were not particularly "quiet".

In addition to single-season occupancy analyses, data derived from repeated aural point counts likely have a number of additional analytical applications beyond those considered here. For instance, repeated sampling both withinseasons (as modeled here) and among seasons (i.e., the robust design) would allow dynamic occupancy modeling with primary and secondary sampling periods (MacKenzie et al. 2005). Dynamic occupancy analysis would allow simultaneous estimation of detection, occupancy, colonization, and local extinction (MacKenzie et al. 2005) and is readily modeled in the same package implemented in our study (R: unmarked, see Kéry and Royle 2015). Additionally, for some species, counts of individuals may be possible (e.g., G. pennsylvanicus), for these countable species, models of abundance may provide a better response variable than species presence with methods like $\mathrm{N}$-mixture models (e.g., Royle 2004; McNeil et al. 2018) or hierarchical distance models (e.g., McNeil et al. 2019). Additionally, community analyses could be conducted where multiple species are modeled together and community-wide metrics can be generated while accounting for heterogeneous rates of detection probability among species (Carrillo-Rubio et al. 2014). 
The evaluation of effective sampling methods for Ensifera as done here is timely in light of global Orthoptera declines (Dirzo et al. 2014; Sánchez-Bayo and Wyckhuys 2019). Although our study was limited in spatial extent, our methods would apply well to studies across larger spatial and temporal extents (e.g., across numerous states, years). Aural point counts could even be combined with citizen science (Dickinson et al. 2010, 2012) where individuals record particular focal species or group of species to collect large amounts of data, perhaps akin to the North American breeding Bird Survey (Sauer et al. 2017) whereby a monitoring program could track population trends over time. Large scale programs might even focus on a few representative species to track long term which might provide insight into the Ensifera community as a whole (Roberge and Angelstam 2004). Our method would also likely be useful for tracking the spread of certain invasive species, indeed, we detected the invasive Japanese Burrowing Cricket on several occasions at some of our highly developed point locations (Supporting Table 2). Additionally, our habitat analysis was very coarse. Further work assessing the impacts of vegetation structure on Ensifera populations might explain more variation than broad cover types alone (Mayor et al. 2009). Work assessing 'full' breeding season song phenology for the species studied here and others would also prove useful-ideally beginning before species begin stridulating and continuing until the cessation of song for all focal species. Ultimately, our study provides clear support for the use of road-side point counts as an effective standardized survey method for night singing Orthoptera of a variety of species, especially when paired with occupancy estimation (Ralph et al. 1995; MacKenzie et al. 2005).

Funding Funding was provided by Penn State Insect Biodiversity Center.

Open Access This article is licensed under a Creative Commons Attribution 4.0 International License, which permits use, sharing, adaptation, distribution and reproduction in any medium or format, as long as you give appropriate credit to the original author(s) and the source, provide a link to the Creative Commons licence, and indicate if changes were made. The images or other third party material in this article are included in the article's Creative Commons licence, unless indicated otherwise in a credit line to the material. If material is not included in the article's Creative Commons licence and your intended use is not permitted by statutory regulation or exceeds the permitted use, you will need to obtain permission directly from the copyright holder. To view a copy of this licence, visit http://creativecommons.org/licenses/by/4.0/.

\section{References}

Albright TA, McWilliams WH, Widmann RH, Butler BJ Crocker SJ, Kurtz CM, Lehman S, Shawn S, Lister TW, Miles R, Morin RS,
Riemann R, Smith JE (2017) Pennsylvania forests 2014. Resour. Bull. NRS-111. U.S. Department of Agriculture, Pennsylvania

Alexander RD, Thomas ES (1959) Systematic and behavioral studies on the crickets of the Nemobius fasciatus group (Orthoptera: Gryllidae: Nemobiinae). Ann Entomol Soc Am 52:592-600

Alexander RD, Pace AE, Otte D (1972) The singing insects of Michigan. Great Lakes Entomol 5:33-69

Andrén H (1994) Effects of habitat fragmentation on birds and mammals in landscapes with different proportions of suitable habitat: a review. Oikos 71:355-366

Bailey WJ (1991) Acoustic behaviour of insects. An evolutionary perspective. Chapman and Hall Ltd, New York

Bazele CS, Thompson AC, Naskrecki P (2016) Testing the efficacy of global biodiversity hotspots for insect conservation: the case of South African katydids. PLoS ONE 11(9):e0160630

Beutenmüller W (1894) Notes on some species of North American Orthoptera, with descriptions of new species. Bull Am Mus Nat Hist 6:11

Bradfer-Lawrence T, Gardner N, Bunnefeld L, Bunnefeld N, Willis SG, Dent DH (2019) Guidelines for the use of acoustic indices in environmental research. Methods Ecol Evol 10:1796-1807

Brouwers NC, Newton AC (2009) Habitat requirements for the conservation of wood cricket (Nemobius sylvestris) (Orthoptera: Gryllidae) on the Isle of Wight, UK. J Insect Conserv 13:529-541

Bruner L (1891) Ten new species of orthoptera from Nebraska-notes on habits, wing variation etc. Can Entomol 23:72

Burmeister H (1838) Handbuch der Entomologi, vol 2. Burmeister, Hermann, p 734

Burnham KP, Anderson DR (2002) Model selection and multimodel inference: a practical information-theoretic approach. Springer, Berlin

Carrillo-Rubio E, Kery M, Morreale SJ, Sullivan PJ, Gardner B, Cooch EG, Lassoie JP (2014) Use of multispecies occupancy models to evaluate the response of bird communities to forest degradation associated with logging. Conserv Biol 28:1034

Cody ML (1985) Habitat selection in birds. Academic Press, New York

Connell JH (1978) Diversity in tropical rain forests and coral reefs. Science 199:1302-1310

Cuff DJ (1989) The atlas of Pennsylvania. Temple University Press, Philadelphia

De Geer C (1773). Mémoires pour servir à l'histoire des insectes 3:522

Dickinson JL, Zuckerberg B, Bonter DN (2010) Citizen science as an ecological research tool: challenges and benefits. Annu Rev Ecol Evol Syst 41:149-172

Dickinson JL, Shirk J, Bonter DN, Bonney R, Crain RL, Martin J, Phillips T, Purcell K (2012) The current state of citizen science as a tool for ecological research and public engagement. Front Ecol Environ 10:291-297

Dirzo R, Young HS, Galetti M, Ceballos G, Isaac NJ, Collen B (2014) Defaunation in the Anthropocene. Science 345:401-406

Diwakar S, Jain M, Balakrishnan R (2007) Psychoacoustic sampling as a reliable, non-invasive method to monitor orthopteran species diversity in tropical forests. Biodivers Conserv 16:4081-4093

Dorcas ME, Price SJ, Walls SC, Barichivich WJ (2009) Auditory monitoring of anuran populations. In: Dodd KC (ed) Amphibian ecology and conservation: a handbook of techniques. Oxford University Press, Oxford, pp 281-298

Elliot L, Hershberger W (2007) Songs of Insects. Houghton Mifflin, Boston

Environmental Systems Research Institute (2011) ArcGIS desktop: release 10. ESRI, Redlands

Ferson S, Burgman M (2006) Quantitative methods for conservation biology. Springer, New York

Fischer FP, Schulz U, Schubert H, Knapp P, Schmöger M (1997) Quantitative assessment of grassland quality: acoustic determination 
of population sizes of orthopteran indicator species. Ecol Appl 7:909-920

Fiske I, Chandler RB (2011) Unmarked: an R package for fitting hierarchical models of wildlife occurrence and abundance. J Stat Softw 43:1-23

Franklin M, Droege S, Dawson D, Royle JA (2009) Nightly and seasonal patterns of calling in common true katydids (Orthoptera: Tettigoniidae: Pterophylla camellifolia). J Orthoptera Res 18:15-18

Fry J, Xian G, Jin S, Dewitz J, Homer C, Yang L, Barnes C, Herold N, Wickham J (2011) Completion of the 2006 National Land Cover Database for the conterminous United States. Photogramm Eng Remote Sensing 77:858-864

Ganchev T, Potamitis I (2007) Automatic acoustic identification of singing insects. Bioacoustics 16:281-328

Gardiner T, Hill J, Chesmore D (2005) Review of the methods frequently used to estimate the abundance of Orthoptera in grassland ecosystems. J Insect Conserv 9:151-173

Gerhardt HC, Huber F (2002) Acoustic communication in insects and anurans: common problems and diverse solutions. University of Chicago Press, Chicago

Gibb R, Browning E, Glover-Kapfer P, Jones KE (2019) Emerging opportunities and challenges for passive acoustics in ecological assessment and monitoring. Methods Ecol Evol 10:169-185

Gooch M, Heupel A, Dorcas M, Price S (2006) The effects of survey protocol on detection probabilities and site occupancy estimates of summer breeding anurans. Appl Herpetol 3:129-142

Gray HE, Treloar AE (1933) On the enumeration of insect populations by the method of net collection. Ecology 14:356-367

Gwynne DT (2001) Katydids and bush-crickets: reproductive behavior and evolution of the Tettigoniidae. Cornell University Press, Ithaca

Hallmann CA, Sorg M, Jongejans E, Siepel H, Hofland N, Schwan H, Stenmans W, Müller A, Sumser H, Hörren T, Goulson D (2017) More than 75 percent decline over 27 years in total flying insect biomass in protected areas. PLoS ONE 12(10):e0185809

Harris TW (1841) Insects of Massachusetts injurious to vegetation. Wells, and Thurston Publishing, Nashville, Folsom

Hochkirch A, Nieto A, Criado MG, Cálix M, Braud Y, Buzzetti FM, Chobanov D, Odé B, Asensio JP, Willemse L, Zuna-Kratky $\mathrm{T}$ et al (2016) European red list of grasshoppers, crickets and bush-crickets. Office of the European Union, Luxembourg

Hugel S (2012) Impact of native forest restoration on endemic crickets and katydids density in Rodrigues island. J Insect Conserv $16: 473-477$

Jantz SM, Barker B, Brooks TM, Chini LP, Huang Q, Moore RM, Noel J, Hurtt GC (2015) Future habitat loss and extinctions driven by land-use change in biodiversity hotspots under four scenarios of climate-change mitigation. Conserv Biol 29:1122-1131

Jeliazkov A, Bas Y, Kerbiriou C, Julien JF, Penone C, Le Viol I (2016) Large-scale semi-automated acoustic monitoring allows to detect temporal decline of bush-crickets. Glob Ecol Conserv 6:208-218

Kéry M, Royle JA (2015) Applied hierarchical modeling in ecology: analysis of distribution, abundance and species richness in $\mathrm{R}$ and BUGS: prelude and static models, vol 1. Academic Press, Cambridge

Knight E, Hannah K, Brigham RM, McCracken J, Falardeau G, Julien M, Guenette J (2016) Canadian nightjar survey protocol. Bird Studies Canada, Ontario

Kozicky EL, Bancroft TA, Homeyer PG (1954) An analysis of woodcock singing ground counts, 1948-1952. J Wildl Manag $18: 259-266$

Leather SR (2017) Ecological Armageddon-more evidence for the drastic decline in insect numbers. Ann Appl Biol 172:1-3
Lebuhn G, Droege S, Connor EF, Gemmill-Herren B, Potts SG, Minckley RL, Griswold T, Jean R, Kula E, Roubik DW, Cane J (2013) Detecting insect pollinator declines on regional and global scales. Conserv Biol 27:113-120

Lehmann GU, Frommolt KH, Lehmann AW, Riede K (2014) Baseline data for automated acoustic monitoring of Orthoptera in a Mediterranean landscape, the Hymettos, Greece. J Insect Conserv 18:909-925

MacKenzie DI (2006) Modeling the probability of resource use: the effect of, and dealing with, detecting a species imperfectly. J Wildl Manag 70:367-374

MacKenzie DI, Nichols JD, Royle JA, Pollock KH, Bailey LL, Hines JE (2005) Occupancy estimation and modeling: inferring patterns and dynamics of species occurrence. Academic Press, Cambridge

Mayor SJ, Schneider DC, Schaefer JA, Mahoney SP (2009) Habitat selection at multiple scales. Ecoscience 16:238-247

Mayor SJ, Cahill JF, He F, Solymos P, Boutin S (2012) Regional boreal biodiversity peaks at intermediate human disturbance. Nature comm 3:1-6

McIntosh EJ, Chapman S, Kearney SG, Williams B, Althor G, Thorn JP, Pressey RL, McKinnon MC, Grenyer R (2018) Absence of evidence for the conservation outcomes of systematic conservation planning around the globe: a systematic map. Environ Evid 7:22

McNeil DJ, Otto CRV, Roloff GJ (2014) Using audio lures to improve golden-winged warbler (Vermivora chrysoptera) detection during point-count surveys. Wildl Soc Bull 38:586-590

McNeil DJ, Fiss CJ, Wood EM, Duchamp J, Bakermans M, Larkin JL (2018) Using a natural reference system to evaluate songbird habitat restoration. Avian Conserv Ecol 13(1):22

McNeil DJ, Otto CRV, Moser EL, Urban-Mead KR, King DE, Rodewald AD, Larkin JL (2019) Distance models as a tool for modelling detection probability and density of native bumble bees. $\mathrm{J}$ Appl Entomol 143:225-235

McNeil DJ, Rodewald AD, Ruiz-Gutierrez V, Johnson KE, StrimasMackey M, Petzinger S, Robinson OJ, Soto GE, Dhondt AA, Larkin JL (2020) Multi-scale drivers of restoration outcomes for an imperiled songbird. Restor Ecol. https://doi.org/10.1111/ rec. 13147

Menz MH, Dixon KW, Hobbs RJ (2013) Hurdles and opportunities for landscape-scale restoration. Science 339:526-527

Montgomery GA, Dunn RR, Fox R, Jongejans E, Leather SR, Saunders ME, Shortall CR, Tingle MW, Wagner DL (2020) Is the insect apocalypse upon us? How to find out. Biol Conserv 241:108327

Nelson GL, Graves BM (2004) Anuran population monitoring: comparison of the North American Amphibian Monitoring Program's calling index with mark-recapture estimates for Rana clamitans. J Herpetol 38:355-359

Orci KM, Szoevenyi G, Nagy B (2010) Isophya sicula sp. n. (Orthoptera: Tettigonioidea), a new, morphologically cryptic bush-cricket species from the Eastern Carpathians (Romania) recognized from its peculiar male calling song. Zootaxa 2627:57-68

Orians GH, Wittenberger JF (1991) Spatial and temporal scales in habitat selection. Am Nat 137:S29-S49

Otto CRV, Bailey LL, Roloff GJ (2013) Improving species occupancy estimation when sampling violates the closure assumption. Ecography 36:1299-1309

Penone C, Le Viol I, Pellissier V, Julien JF, Bas Y, Kerbiriou C (2013) Use of large-scale acoustic monitoring to assess anthropogenic pressures on orthoptera communities. Conserv Biol 27:979-987

Potts SG, Biesmeijer JC, Bommarco R, Felicioli A, Fischer M, Jokinen P, Kleijn D, Klein AM, Kunin WE, Neumann P, Penev LD (2011) Developing European conservation and mitigation tools for pollination services: approaches of the STEP (Status and Trends of European Pollinators) project. J Apic Res 50:152-164 
R Core Team (2020) R: a language and environment for statistical computing. R Foundation for Statistical Computing. Vienna, Austria. https://www.R-project.org/

Rahim M (2016) Comparisons of line transect and point count survey methods by estimating density of grey squirrel Sciurus carolinensis. J Ecol Environ 7:17-28

Ralph CJ, Sauer JR, Droege S (1995) Monitoring bird populations by point counts. General technical report PSW-GTR-149. US Forest Service Pacific Southwest Research Statio, Albany

Riede K (1998) Acoustic monitoring of Orthoptera and its potential for conservation. J Insect Conserv 2:217-223

Riede K (2018) Acoustic profiling of Orthoptera. J Orthoptera Res 27:203-215

Riley CV (1881) Fifth Annual Report of the Noxious, Beneficial, and Other Insects of the State of Missouri. State Board of Agriculture, p 61

Roberge JM, Angelstam PER (2004) Usefulness of the umbrella species concept as a conservation tool. Conserv Biol 18:76-85

Rose OC, Brookes MI, Mallet JLB (1994) A quick and simple nonlethal method for extracting DNA from butterfly wings. Mol Ecol $3: 275-275$

Royle JA (2004) N-mixture models for estimating population size from spatially replicated counts. Biometrics 60:108-115

Sánchez-Bayo F, Wyckhuys KA (2019) Worldwide decline of the entomofauna: a review of its drivers. Biol Conserv 232:8-27

Sauer JR, Niven DK, Hines JE, Ziolkowski DJ, Pardieck KL, Fallon JE, Link WA (2017) The North American Breeding Bird Survey, Results and Analysis 1966-2015. Version 2.07.2017 USGS Patuxent Wildlife Research Center, Laurel

Saussure AH (1859) Revue et Magasin de Zoologie 2:204

Scudder SH (1877) Proceedings of the Boston Society of. Nat Hist 19:36

Scudder SH (1878) Proceedings of the Boston Society of. Nat Hist 20:93

Shapiro LH (1998) Hybridization and geographic variation in two meadow katydid contact zones. Evolution 52:784-796

Shaw KC (1968) An analysis of the phonoresponse of males of the true katydid, Pterophylla camellifolia (Fabricius)(Orthoptera: Tettigoniidae). Behaviour 31:203-259
Shaw KC, Carlson OV (1969) The true katydid, Pterophylla camellifolia (Fabricius)(Orthoptera: Tettigoniidae) in Iowa: two populations which differ in behavior and morphology. Iowa State Coll J Sci 44:193-200

Shaw KC, Bitzer RJ, North RC (1982) Spacing and movement of Neoconocephalus ensiger males (Conocephalinae: Tettigoniidae). $\mathrm{J}$ Kans Entomol Soc 55:581-592

Shultz CH (1999) The geology of Pennsylvania. Pennsylvania Geological Survey, Harrisburg

Sokal RR, Rohlf FJ (1969) The principles and practice of statistics in biological research. W.H Freeman and Company, San Francisco

Spafford RD, Lortie CJ (2013) Sweeping beauty: is grassland arthropod community composition effectively estimated by sweep netting? Ecol Evol 3:3347-3358

Taron D, Ries L (2015) Butterfly monitoring for conservation. In: Daniels JC (ed) Butterfly conservation in North America. Springer, Switzerland, pp 35-57

Taylor SJ, Krejca JK, Denight ML (2005) Foraging range and habitat use of Ceuthophilus secretus (Orthoptera: Rhaphidophoridae), a key trogloxene in central Texas cave communities. Am Midl Nat 154:97-114

Thomas JA (2005) Monitoring change in the abundance and distribution of insects using butterflies and other indicator groups. Philos Trans R Soc B 360:339-357

Thomas JA (2016) Butterfly communities under threat. Science 353:216-218

Uhler PR (1864) Proc Entomol Soc Phila 2:545

van Klink R, Bowler DE, Gongalsky KB, Swengel AB, Gentile A, Chase JM (2020) Meta-analysis reveals declines in terrestrial but increases in freshwater insect abundances. Science 368:417-420

Wilson AM, Brauning DW, Mulvihill RS (2012) Second Atlas of breeding birds in Pennsylvania. The Pennsylvania State University Press, Pennsylvania

Yoccoz NG, Nichols JD, Boulinier T (2001) Monitoring of biological diversity in space and time. Trends Ecol Evol 16:446-453

Publisher's Note Springer Nature remains neutral with regard to jurisdictional claims in published maps and institutional affiliations. 